\title{
G6PD-Deficient Erythrocytes to Erythrocytes Ratio Measurement
}

National Cancer Institute

\section{Source}

National Cancer Institute. G6PD-Deficient Erythrocytes to Erythrocytes Ratio

Measurement. NCI Thesaurus. Code C132369.

The determination of the ratio of the G6PD-deficient erythrocytes as compared to the total erythrocytes present in a sample. The measurement may be expressed as a ratio or percentage. 